\title{
The Signs of alert and Labor: knowledge among pregnant women
}

Hevyllin Cipriano Rodrigues Félix 1

D https://orcid.org/0000-0002-8186-9116

Carolina Camargos Corrêa 2

https://orcid.org/0000-0002-3983-7655

Thais Gabriela da Cruz Matias 3

https://orcid.org/0000-0003-4084-2459

Bibiane Dias Miranda Parreira 4

https://orcid.org/0000-0001-7369-5745

Marina Carvalho Paschoini 5

(iD) https://orcid.org/0000-0003-2218-4747

Mariana Torreglosa Ruiz 6

https://orcid.org/0000-0002-5199-7328

1-6 Universidade Federal do Triângulo Mineiro. Praça Manoel Terra, 330, Abadia. Uberaba, MG, Brasil. CEP: 38.025-200. E-mail: marianatorreglosa@hotmail.com

\begin{abstract}
Objectives: identify the scores on the pregnant women's knowledge on the signs of alert and labor and correlate the scores with the maternal age, number of children and the guidance they received during pregnancy.

Methods: this is a descriptive, cross-sectional study with a quantitative approach on pregnant women's previous knowledge of the signs of alert and labor performed with 100 pregnant women on their 30th week of gestation at the Hospital de Clinicas da UFTM (Clinical Hospital). The data collection was carried out from April to June 2016, using a semi-structured instrument tested as a pilot study.

Results: only $21 \%$ of the pregnant women reported taking part in the pregnant women's group; $61 \%$ of them referred to not receiving any information on the signs of alert and labor. A statistically significant association was verified between the number of correct answers and the guidance they received during prenatal consultations. However, there was no correlation between the correct scores on maternal age and the number of children.

Conclusions: the pregnant women who did not receive any kind of guidance, they had lower scores on the correct answers, which shows the importance of guiding them about Health Education during their prenatal consultations.
\end{abstract}

Key words Prenatal care, Obstetric childbirth, Labor, Health education 


\section{Introduction}

Health education is an important tool in assisting the pregnancy-puerperal cycle since pregnancy is a delicate period and generates potential doubts and anxiety for the parents and their family members. ${ }^{1}$

As it is known, the practice of health education in the prenatal care can be developed in various ways, such as lectures, groups and educational actions both collective and individual (during the consultations) ${ }^{1}$ and among the topics to be addressed, recognizing the signs of alert and labor. These guidance aim to reduce the parturients' hospitalization time, reduce the risk of errors in identifying dystocia, unnecessary interventions and operative childbirths. ${ }^{2}$

It is noteworthy that, despite the diffusion of current information, women are still unaware of the signs of alert and labor symptoms, confusing the exact moment they should look for a maternity. Therefore, it is up to the health professional to inform them about the signs of alert, such as vaginal bleeding, headache, visual disorders, abdominal pain, fever, vaginal losses, respiratory distress, and among others. ${ }^{2}$

One should also differentiate the true and false labor. Recognition of the first one consists of the presence of uterine contractions that occurs one every three to five minutes, lasting from 20 to 60 seconds, at regular intervals that gradually increases as referred to the frequency and the intensity. It should be noted that, once the labor has begun, the uterine contractions do not cease and consequently, the uterine cervix dilates. 3

In a false labor, also referred to as Braxton-Hicks contractions, there are irregular contractions and dilation of the cervix which does not occur concomitantly. By the thirtieth week of gestation, the false contractions appear more frequently and may cause a possible misunderstanding and generate doubts, mainly in the nulliparas. ${ }^{3}$

From this perspective, the professionals' work becomes imperative through health education. The professionals should welcome the pregnant women and their family members, increase the quality of care and make it more humanized by promoting well-being and above all, autonomy and consequently, reducing their anxiety, fears and doubts about pregnancy, childbirth and the puerperium. ${ }^{2}$

Based on the premise that the healthcare professional should be responsible to inform the pregnant women about the signs and symptoms of labor, it is expected that such knowledge would be disseminated during the prenatal care. The reduction of women's hospitalizations due to false labor tends to reduce premature admissions, shorten length of hospital stay, avoid the risk of healthcare related infections, as well as the use of unnecessary interventions. 1

Due to the relevance, in addition to the negative impacts on the parturient's premature admissions that potentially generates unnecessary interventions, increases the risk of infections due to the lack of information about the signs of alert and labor and the scarce of studies about the issue justifies the completion of this study.

This study had guiding questions, such as: Are pregnant women informed during prenatal care about the signs of alert and labor? As they receive these information, do they recognize these signs? Is there a correlation between the scores on knowledge about the subject and the maternal age, and/or the number of children and/or the fact that they have received any kind of information during their pregnancy?

Thus, the objective of this study was to identify the scores on the pregnant women's knowledge about the signs of alert and labor and correlate the scores on the correct answers on maternal age, number of children and the information received during their pregnancy.

\section{Methods}

This is a descriptive and cross-sectional study, with a quantitative approach, about the pregnant women's prior knowledge about the signs of alert and labor and the correlated factors. This study was carried out at a teaching hospital, which it is a reference for high-risk prenatal care in the city of Uberaba (MG) and its regions, composed by 27 cities, and for the habitual residents with risky gestation in District I of the city (population estimated at 150,000 inhabitants)

The participants in the study were pregnant, at their $30^{\text {th }}$ gestational week regardless of age, and those under the age of 18 were authorized by legal guardians to consent. The pregnant women whose unborn child had malformations incompatible with life and/or the outcome was abortion, fetal death or stillbirth were excluded from the study.

A total of 100 pregnant women were included in the study. For the determination of the sample size, the PASS (Power Analysis and Sample Size) application, version of 2002 was used, introducing the following values and information: a priori determination coefficient $\mathrm{R}^{2}=0.13$ in a linear regression model with three predictors was considered. This 
coefficient was introduced according to the Cohen classification (Sample Size in Behavioral Sciences), hoping to find a strong relation between knowledge and the predictors of interest (maternal age, number of children and prior knowledge - received information at the prenatal consultation), had a level of significance, $\alpha \leq 0.05$. A sample size of at least 99 subjects was obtained. The dependent variable was the score of the pregnant women's knowledge regarding to the signs of alert and labor and the independent ones considered in the analysis were the maternal age, the number of children and received guidance during their pregnancy.

The researchers approached the pregnant women in the waiting room, before or after the prenatal consultation, oriented them on the objectives of the study and invited them to participate, according to the established inclusion and exclusion criteria. The data collection was carried out in a consulting room provided by the institution, respecting the principles of secrecy and privacy.

The socio-demographic, health conditions, the past and present obstetric history data were collected from the interviews or from the medical records. In relation to the knowledge about the signs of alert and labor, the pregnant women answered a specific instrument, composed by 10 questions, each of which had four alternative answers, having only one correct answer. The participants' knowledge was measured by the total of correct answers.

Regarding the objective that corresponds to the previous knowledge/guidance, it was taken in consideration when the pregnant woman informed that she had participated in a group of pregnant women, received individual guidance during the consultations, participated in lectures or in the waiting rooms during their pregnancy. The pregnant women could answer to the researchers or by writing in the questionnaire

The data collection instruments were constructed by the authors themselves based on a literature review on the subject and submitted to the judges for evaluation. Three professionals from the area, who were not part of the study team and who met the following criteria, were invited to act as judges: 1 - a specialist in the area of Obstetrics; 2 - have at least five years of professional experiences; 3- work with healthcare and/or teaching. The judges evaluated the clarity and relevance of the content of the instrument, and each of the variables/questions contained two alternatives (yes and no) for the relevance and clarity of the statements. The questionnaire was accompanied by a term clarifying the objectives of the study and the activities requested by the researchers for the judges. Validated questions/variables were taken in consi-deration those that obtained a concordance index equal or superior to $70 \%$ in the judges' answers for pertinence and clarity. After the judges' validation, the collection form was tested by a pilot study with ten pregnant women, and the instruments collected in this study were excluded from the analysis. There was no inclusion or exclusion of the variables after the pilot test, as all the variables of the instrument were adequate to respond the objectives of this study.

The questions concerning the signs of alert and labor have addressed the following topics: 1- signs that precede labor; 2 - loss and mucus plug characteristics; 3 - how to identify the amniotic membranes; 4- amniotic fluid characteristics; 5 - how to proceed after the water breaks (amniotic membranes); 6 how to proceed during vaginal bleeding; 7 - procedure in recognizing uterine dynamics; 8 - factors that do not influence/interfere with uterine contractility; 9 - what to do with the reduction of fetal movement and 10 - what are the signs of pregnancy complications.

The data collected was stored in an Excel® format database and later imported to the Statistical Package for the Social Sciences program, version 23.0 for processing and analysis. The variables were analyzed from the descriptive statistics. Pearson's chi-square test was used to determine the correlation between the scores about knowledge on labor and the signs of alert and prior guidance/information variables during prenatal care, maternal age and number of children, to determine the actual association of the variables with the knowledge on the subject, the data were analyzed by linear regression.

The research was approved by the Research Ethics Committee at the Universidade Federal do Triângulo Mineiro under the document number $1,282,397$ on October 15, 2015. All the development was guided by the Guidelines and Norms Regulating Research involving human beings, contained in Resolution number 466/12/ National Health Council/ Ministry of Health.

\section{Results}

The interviewed pregnant women's mean age was $28.2 \pm 7.0$ years, ranging from 14 to 45 years old. Of these, $5 \%$ were adolescents and $18 \%$ were equal to or older than 35 years old. The majority affirmed to have a stable relationship (85\%), are not employed $(60 \%)$ and do not have their own income $(61 \%)$. Regarding to their self-report on skin color, $40 \%$ declared themselves mixed, $28 \%$ white and $26 \%$ 
black and, in terms of schooling, the answers were heterogeneous, incomplete elementary schooling (27\%) and concluded high school (27\%).

Regarding habits and living conditions, $10 \%$ reported they consumed alcohol drinks and 12\% were smokers. In relation to health problems, $22 \%$ had some kind of disease prior to the pregnancy, the highest frequency was hypertensive syndromes (18.2\%) and diabetes (13.6\%); $28 \%$ had some type of complication during pregnancy, the most mentioned was preterm labor $(21.4 \%)$, bleeding (17.9\%) and gestational diabetes (14.3\%).

The obstetric data revealed that the mean gestational age at the time of the interview was $34.7 \pm 3.1$ ranging from 30 to 40 weeks of gestation; the mean number of pregnancies was $2.9 \pm 1.8$, ranging from one to ten pregnancies, with a predominance of secondary pregnancies $(28 \%)$; the mean number of prenatal consultations was $7.4 \pm 2.7$, ranging from one to 16 consultations. The mean number of live children was $1.5 \pm 1.6$, ranging from zero to seven children per pregnant woman.

When was asked if the women had participated in a pregnant women's group in their communities, only $21 \%$ reported that they had participated, and when they were questioned about the professional guidance on the signs of alert and labor during prenatal care, $61 \%$ reported that they did not receive any kind of information.

The number of correct answers in relation to the ten questions concerning knowledge about the signs of alert and labor varied from one to nine, with a mean of $4.9 \pm 2.0$ correct answers, and only $39 \%$ of the pregnant women got at least $50 \%$ of the questions correct.
These answers indicated that: $68 \%$ could not identify the signs that precede labor; $63 \%$ had information about the loss of the mucus plug as a premonitory signal rather than labor; $63 \%$ of the pregnant women did not know the signs of the water breaking (amniocoronic membranes); $72 \%$ did not know the amniotic fluid characteristics and $68 \%$ did not know what to do if the water broke; $90 \%$ acknowledged that bleeding is a sign of alert and should be promptly evaluated by a healthcare team; $58 \%$ were guided to recognize uterine dynamics and the signs of labor; however, $65 \%$ did not identify factors that interfere in the contractions leading to false labor; $68 \%$ were unable to inform about normality or impaired fetal movement, and $87 \%$ were able to distinguish the symptoms of complications that need to be assessed during pregnancy (Table 1).

Pearson's chi-square test was used to determine the association between prior knowledge/guidance, maternal age, number of children and current knowledge about the signs of alert and labor. As a cutoff point, the number of corrections was considered superior or inferior to $50 \%$. It was possible to verify that there was a statistical significance $(p=0.015)$ only between the number of correct answers (correct answers greater than 50\%) and the guidance received during prenatal care, in other words: women who did not receive any guidance had lower scores on the correct answers and the other variables did not present statistical significance, as it can be observed in Table 2.

To determine the real association between the variables, regardless of the statistical significance, the linear regression model was used. Only the variable that received prenatal guidance remained asso-

Table 1

Frequency of the variables on the knowledge of the signs of alert and labor of 100 pregnant women that were interviewed, Uberaba, MG, Brazil, 2016.

\begin{tabular}{llc}
\hline & Correct answers (n) & Wrong answers (n) \\
\hline 1. Signs that precede labor & 32 & 68 \\
2. Mucus plug & 63 & 37 \\
3. Water breaking & 37 & 63 \\
4. Characteristics of amniotic fluid & 23 & 72 \\
5. What to do when the water breaks & 31 & 68 \\
6. Bleeding & 90 & 9 \\
7. Recognize the dynamics of the uterus & 58 & 41 \\
8. Factors that do not interfere with contraction & 34 & 65 \\
9. Fetal movement & 31 & 68 \\
10. Signs of complications & 87 & 12 \\
\hline
\end{tabular}

Source: Research data, 2016. 
ciated to the higher scores on knowledge on the signs of alert and labor (Table 3 ), indicating that health education during pregnancy influences knowledge regardless of age and the number of children.

\section{Table 2}

Association between the percentage of correct answers and maternal age, the number of children and prenatal guidance, Uberaba, MG, Brazil, 2016*.

\begin{tabular}{|c|c|c|c|c|c|}
\hline Variables & $\begin{array}{l}\text { Correct answers } \\
\quad>50 \% \text { (n) }\end{array}$ & $\%$ & $\begin{array}{c}\text { Wrong answers } \\
<50 \% \text { (n) }\end{array}$ & $\%$ & $p$ \\
\hline Age over 35 years old & 6 & 6 & 14 & 14 & 0.361 \\
\hline Age under 35 years old & 33 & 33 & 47 & 47 & \\
\hline One child & 12 & 12 & 21 & 21 & 0.708 \\
\hline More than one child & 27 & 27 & 40 & 40 & \\
\hline Received guidance during prenatal care & 21 & 22 & 18 & 19 & 0.015 \\
\hline Did not receive any guidance & 17 & 18 & 41 & 42 & \\
\hline
\end{tabular}

* Pearson's chi-square test, $p \leq 0.05$; Source: Research data, 2016.

Table 3

Linear regression analysis on knowledge about the signs of alert and labor by pregnant women, associated to maternal age, number of children and received guidance during prenatal care, Uberaba, MG, Brazil, 2016.

\begin{tabular}{lcc}
\hline Variables & $\boldsymbol{\beta}$ & $\boldsymbol{p}$ \\
\hline Maternal age & 0.004 & 0.968 \\
Number of children & 0.152 & 0.170 \\
Receive guidance during prenatal care (yes / no) & 0.274 & 0.009 \\
\hline
\end{tabular}

* Linear regression model; Source: Research data, 2016.

\section{Discussion}

In relation to prenatal care, it is noteworthy that most of the pregnant women performed an adequate number of prenatal consultations. At least six consultations are indicated for an ideal assistance, according to the Prenatal and Birth Humanization Program, with at least one being performed in the first trimester; two in the second and three in the third. ${ }^{2}$

In a study that evaluated prenatal care in a Brazilian city, $90 \%$ performed prenatal care adequately (more than six consultations); $40 \%$ in the beginning of the first trimester of pregnancy, and all the pregnant women underwent all the basic laboratory tests and had tetanus coverage. However, when analyzing the frequency of educational activities, only $11 \%$ of the pregnant women participated in some educational action during pregnancy, receiving the lowest frequency score among all evaluated items, ${ }^{4}$ pointing out the need of improving the quality of care, regardless of the number of consulta- tions, as the data in this study.

Most of the pregnant women that were interviewed reported that they did not receive any kind of guidance on the signs of alert and labor during their prenatal care. Thus, addressing pregnant women on prenatal consultations, a study showed that they were restricted to prenatal care, such as performing physical examination and requesting laboratory tests, but not highlighting educational aspects, especially when relating to the signs alert and labor. 5

In contrast to the data presented, a study on health education during pregnancy indicated that $56.4 \%$ reported they had received guidance on the signs of labor by health professionals, and the nurse was the most cited professional 6 in being the educator.

The literature also highlights that in this process of Health Education, the partners are of fundamental importance, because when they are guided, they can identify the signs of labor and the moment to lead the pregnant women to the maternity, as well as recognize with clarity the signs of alert. In a study 
carried out with the pregnant women's partners, when they were asked about the knowledge on the issue, they reported the necessity of counting the contractions in ten minutes verifying the frequency and pointing out the presence, of at least, three contractions and the need of evaluating in case of bleeding. As the partners mentioned in their own words, it is clear how important it is to recognize these signs and symptoms in order to avoid the unnecessary trip to the maternity. ${ }^{7}$

Although, this is not the objective of the study, but it is important to emphasize the importance of the pregnant women's partners and their social support in understanding the signs of alert and labor. In order to increase the partners' knowledge not only about the time of the childbirth, but also about their actions, what signs precede labor and when to go to the maternity, there is an educational material entitled "Preparing yourself to accompany a natural birth: What is important to know?". Both the content and the appearance of the material were validated by peers and everyone else. ${ }^{8}$ Initiatives such as this facilitates the pregnant women and their families' in understanding and increases their knowledge since the material has a clear language it can be shared within the pregnant woman's social circle and it is believed that the greater the number of people are guided, the lower the chances of early or unnecessary hospitalization due to the lack of information.

One study showed that about two-thirds of the pregnant women reported that vaginal bleeding, severe abdominal pain or severe contractions were alerts for immediate search for a prompt assistance for care; $46 \%$ reported that the water breaking indicated severity, regardless of the characteristic of the liquid; 21 to $26 \%$ indicated that loss of amniotic fluid or mucus plug, as well as the pressure increased, indicated immediate need for assistance of care. Only one in ten pregnant women signaled that the absence of fetal movements would indicate severity in the gestational period showing a great lack of knowledge regarding to the issue. ${ }^{9}$ The data are similar to those found in the study that indicated a discrepancy in recognizing signs that precede labor; identifying and proceeding in relation to when the water breaks; and to identify changes in fetal movement and uterine contractions. However, in the same way, the pregnant women recognized the necessity of evaluating when the bleeding occurred and they knew how to identify potential complications.

Qualitative research indicated that some pregnant women arrived at the maternity without receiving any information during prenatal care on labor and this occurred more frequently among multiparous women. The authors considered that many health professionals believe that multiparous women had already received some information in previous pregnancies, ignoring the need in reviewing the pregnant women's knowledge and completing it. 10 However, in the studied sample, the recognition on the signs of alert and labor, it did not present any statistical association with the number of children.

It should be emphasized that the prenatal followup period is the propitious moment for the health professional, as a relevant role as a health educator, to influence the pregnant woman. During this period, the professional should offer support in guiding the pregnant woman in relation to the entire gestational process and its outcome, in order to increase safety and reduce anxiety. 11 In addition, prenatal care satisfaction is directly related to the guidance received during the consultations. 12 This information can be highlighted by the fact that, when adolescent pregnant women are interviewed, they consider prenatal care satisfactory due to how the health team are attentive during the assistance and the guidance given to them. 13

The limitations of this study were related to the method used, as this is a descriptive and crosssectional study, and as it regards to the external validity, the data cannot be generalized to other realities. Based on the results found, it is emphasized that new studies can be carried out, that these results are proven through hypothesis tests or different outlined designs are used. In addition, there is a shortage of studies in the literature on this issue, which makes it difficult to discuss and compare the data that was found.

The data presented in this study made it possible to outline a profile on pregnant women who were assisted at the teaching hospital, as well as to detect the necessity to provide health education and the importance of guidance on the signs of alert and labor for this population. From the results, the issue on guidance can be established, both in the institution where the study was carried out and in other institutions, since, in comparison with other studies; this necessity in providing health education is identified in different contexts and institutions.

Most of the pregnant women did not receive any guidance on the signs of alert and labor during their prenatal care, reflexing on the answers related to the issue. There was a greater discrepancy in recognizing the preliminary signs; identifying and proceeding in relation to the water breaking, identifying changes in the fetal movement and uterine contractions. However, they recognize the necessity 
of evaluating the presence of bleeding and they know how to identify potential complications.

The recognition of the signs of alert and labor was not associated to the age of the pregnant woman and the number of children. The pregnant women who did not receive any guidance had lower scores on the correct answers, and there was a statistically significant association between receiving guidance on the issue during their prenatal care and the percentage of correct answers, confirmed by the linear regression, demonstrating the importance of providing Health Education during prenatal care.

\section{Acknowledgements}

Financial Support - Bolsa de Iniciação Científica FAPEMIG - (Scientific Initiation Grant) Fundação de Apoio à Pesquisa (Research Support Foundation) in Minas Gerais

\section{References}

1. Guerreiro EM, Rodrigues DP, Queiroz ABA, Ferreira MA. Educação em saúde no ciclo gravídico-puerperal: sentidos atribuídos por puérperas. Rev Bras Enferm. 2014; 67 (1): 13-21.

2. Brasil. Ministério da Saúde. Secretaria de Atenção à Saúde. Departamento de Atenção Básica. Atenção ao pré-natal de baixo risco. Cadernos de Atenção Básica n 32. Brasília, DF; 2012.

3. Rezende J, Montenegro CAB. Obstetrícia Fundamental. 13 ed. Rio de Janeiro: Guanabara Koogan; 2014.

4. Silva EP, Lima RT, Ferreira NLS, Carvalho e Costa MJ. Pré-natal na atenção primária do município de João Pessoa - PB: caracterização de serviços e usuários. Rev Bras Saúde Matern Infant. 2013; 13 (1): 29-37.

5. Pohlmann FC, Kerber NPC, Pelzer MT, Dominguez CC, Minasi JM, Carvalho VF. Modelo de assistência pré-natal no extremo sul do país. Texto Contexto Enferm. 2016; 25 (1): e3680013.

6. Oliveira LFM, Davim RMB, Alves ÉSRC, Rodrigues ESRC, Nóbrega MF, Torquato JA. Vivência de puéperas adolescentes quanto à gravidez e trabalho de parto. Rev Enferm UFPE. 2016; 10 (2): 395-406.

7. Melo RM, Angelo BHB, Pontes CM, Brito RS. Men's knowledge of labor and childbirth. Esc Anna Nery. 2015; 19 (3): 454-459.

\section{Received on February 3, 2018}

Final version presented on November 21, 2018

Approved on March 28, 2019

\section{Authors' contributions}

The authors, Corrêa CC, Félix HCR, Matias TGC, Parreira BDM, Paschoini MC and Ruiz MT participated in these steps: 1. Substantial contributions to design and outline, data collection or analysis and interpretation of the data; 2 . Writing of the article or critical review on relevant and intellectual content and 3. Approval on the final version to be published.

8. Teles LMR, Oliveira AS, Campos FC, Lima TM, Costa CC, Gomes LFS, et al. Construção e validação de material educativo para acompanhantes durante o trabalho de parto e parto. Rev Esc Enferm USP. 2014; 48 (6): 977-84.

9. Sassi-Mendoza RA, Cesar JA, Ulmi EF, Mano OS, Dall'Agnol MM, Neumann NA. Avaliando o conhecimento sobre pré-natal e situações de risco à gravidezes entre gestantes residentes na periferia da cidade de Rio Grande, Rio Grande do Sul, Brasil. Cad Saúde Pública. 2007; 23 (9): 2157-66.

10. Brito CA, Silva ASS, Cruz RSBL, Pinto SL. Percepções de puérperas sobre a preparação para o parto no pré-natal. Rev Rene. 2015; 16 (4): 470-8.

11. Silva SPC, Prates RCG, Campelo BQA. Parto normal ou cesariana? Fatores que influenciam na escolha da gestante. Rev Enferm UFSM. 2014; 4(1): 1-9.

12. Jorge HMF, Hipólito MCV, Masson VA, Silva RM. Prenatal care and public policies for women's health: integrative review. Rev Bras Promoç Saúde. 2015; 28 (1): 140-8.

13. Luz NF, Assis TR, Rezende FR. Puérperas adolescentes: percepções relacionadas ao pré-natal e ao parto. ABCS Health Sci. 2015; 40 (2): 80-4. 